\title{
Effectiveness of Contact Tracing of Index Tuberculosis Cases in Nigeria
}

\author{
Okorie Onuka1, Ikpeazu Okezie², John Ahukanna ${ }^{3}$, Chukwudi Okebaram4, Patrick Dakum5, \\ Aderonke Agbaje5, Vivian Ibeziako5, Gidado Mustapha6, Nkem Chukwueme6, \\ Emperor Ubochioma7, Amarachi Okorie ${ }^{8}$, Nwafor Charles ${ }^{9}$, Chux Anago ${ }^{10}$
}

\author{
${ }^{1}$ TB Control Program, Ministry of Health, Abia State, Nigeria \\ ${ }^{2}$ Abia State Government House, Umuahia, Abia State, Nigeria \\ ${ }^{3}$ Ministry of Health, Abia State, Nigeria \\ ${ }^{4}$ Department of Pharmacology and Therapeutics, Abia State University, Uturu, Nigeria \\ ${ }^{5}$ Institute of Human Virology, Abuja, Nigeria \\ ${ }^{6} \mathrm{KNCV}$, Abuja, Nigeria \\ ${ }^{7}$ National TB Control Program, Abuja, Nigeria \\ ${ }^{8}$ School of Midwifery, Ministry of Health, Umuahia, Nigeria \\ ${ }^{9}$ GLRA Enugu, Enugu, Nigeria \\ ${ }^{10}$ Clinton Health Access Initiative, Abuja, Nigeria \\ Email: onphil200@yahoo.co.uk
}

How to cite this paper: Onuka, O., Okezie, I., Ahukanna, J., Okebaram, C., Dakum, P., Agbaje, A., Ibeziako, V., Mustapha, G., Chukwueme, N., Ubochioma, E., Okorie, A., Charles, N. and Anago, C. (2018) Effectiveness of Contact Tracing of Index Tuberculosis Cases in Nigeria. Advances in Infectious Diseases, 8, 173-199. https://doi.org/10.4236/aid.2018.84016

Received: July 1, 2018

Accepted: November 5, 2018

Published: November 8, 2018

Copyright $\odot 2018$ by authors and Scientific Research Publishing Inc. This work is licensed under the Creative Commons Attribution International License (CC BY 4.0).

http://creativecommons.org/licenses/by/4.0/ (c) (i) Open Access

\begin{abstract}
Tuberculosis (TB) is a chronic disease that has impacted negatively on human history. The biology of the mycobacterium tuberculosis is complicated and has affected the control as well as elimination of the disease. Nigeria is one of the countries with high incidence and prevalence of TB. The late and low case detection has been a major problem with National TB control program, caused by passive case finding strategy practiced by the country. A shift from the passive and active case search has been recommended for detection of missing cases of TB and improved program performance. The proximity of TB contact is a major determinant of disease transmission. However, maximizing early case detection and prompt treatment of notified cases is very useful in (TB) control especially in high burden countries. The tracking of TB contacts provides a good platform for early diagnosis, educating the household on TB disease and infection control as well as breaking the chain of transmission. The objective of the study is to ascertain effectiveness of contact tracing on Tuberculosis case detection. The study is a retrospective quasi experimental with quantitative arm. The study was conducted in Abia State, one of the South Eastern States of Nigeria. A pre-tested questionnaire was used for data collection and analyzed with SPSS. A total of 168 and 162 index cases of TB were recruited for both intervention and control facilities. The 168 index
\end{abstract}


TB cases yielded $301 \mathrm{~TB}$ contacts. The result revealed 55\% contact/index ratio, presumptive TB yield of $130(43.2 \%)$ and TB yield of 68 (22.6\%). The cases registered in the State increased from 336 to 417 and $\mathrm{p}$ value $=0.001$, while presumptive $\mathrm{TB}$ and $\mathrm{BCG}$ vaccination were major predictors. The study shows that tracing contact of index TB cases is an effective and complementary method of finding undetected cases of TB.

\section{Keywords}

Contact Tracing, Index TB Cases

\section{Introduction}

Maximizing early case detection, prompt and effective treatment of tuberculosis are critical strategies for Tuberculosis (TB) control especially in high burden countries [1]. Early case finding is one of the pillars of End TB strategy approved by WHO for National TB control programmes to implement [2]. The strategy is an effective secondary prevention method for managing sub-clinical manifestation and transmission of TB [3]. The close proximity of Household or workplace contacts to an index TB case is a major predisposing factor to TB transmission and infection [4]. A contact of index TB case is defined, as a person living with an infectious TB case over a period of three months before diagnosis [4]. Searching for these contacts as part of active case finding strategy by the National Tuberculosis control program provides a useful opportunity for detecting undiagnosed TB cases [1]. The international standard for TB care recommends that countries with high or low burden of TB should adopt contact tracing of index TB cases as part of routine case finding activity [5]. However, despite the novelty and uniqueness of the strategy most of the National and sub-National tuberculosis control programs are yet to embrace the strategy due to limited resources and lack of trained staff [6]. The tracking of TB contacts provides a good platform for early diagnosis, educating the household on TB disease and infection control as well as breaking the chain of transmission [1].

Prioritizing contact tracing of TB cases in high burden rural areas is a positive step to harvesting new cases of TB [7]. [8] posits that contact tracing is a cost-effective strategy in low burden TB countries, however [9] maintained that the strategy is considerably cost effective in countries with high prevalence of TB.

$\mathrm{TB}$ is a longstanding disease that has plagued human history and remains a global challenge especially in developing and low-income countries. The disease was termed consumption and 75\% of four million deaths in England and Wales from 1851 to 1910 were credited to TB [10]. The biology of mycobacterium tuberculosis is complicated and has influenced the control as well as elimination of the disease [11]. TB is a major public health concern, and one of the ten diseases in Nigeria with high morbidity and mortality [12]. Despite the adoption and 
implementation of directly observed treatment (DOT) and stop TB strategy, the incidence and prevalence of the disease has shown an upward trajectory, especially in sub-Saharan Africa [13]. However, WHO approved the End TB strategy for post-2015 TB control for elimination and eradication of the disease (WHO, 2017a) [2]. The strategy is aimed at reducing the death rate by $90 \%$, incidence rate by $80 \%$ and no catastrophic cost by 2030 [2]. The pillars of the strategy are early case detection for susceptible and drug resistant $\mathrm{TB}$, contact tracing of index TB cases and screening of high risk population [2].

\subsection{Barriers to TB Case Detection in Nigeria}

Low case detection of TB is a global challenge and a major cause of prolonged transmission of TB as one infectious TB case has a probability of infecting more than 15 persons annually [14]. Delayed and low TB case detection has been a major setback to TB control in Nigeria [15]. Many factors such as poor access, stigmatization, inadequate human resources and insufficient direct observed treatment and diagnostic centers have been associated with low case notification [16].

[17] opined that poor health seeking behaviors among presumptive TB cases was responsible for delayed diagnosis of TB. In addition, [18] noted that TB case detection is affected by limitation of Ziehl Nelson techniques as $50 \%$ of the cases are missed due to low sensitivity. More so, [19] noted that TB case detection in Nigeria has been suboptimal due to low awareness by relevant stakeholders. Furthermore, [20] noted that poor knowledge of TB in community impede presumptive $\mathrm{TB}$ case referral and early case finding.

The case detection approach in most high burden countries including Nigeria is passive; this is affected by low knowledge of TB and poor health seeking behavior which invariably affects case finding [21]. Though diagnosis and treatment of TB is free however hidden and catastrophic cost incurred by patients affects health seeking behavior [22].

\subsection{Current Strategies to End TB}

The WHO had recommended many strategies for the control of TB over the years. These include the Directly Observed Treatment and Stop TB strategy [23]. These strategies were adopted and implemented by the National Tuberculosis programs of different countries. The underperformance of the two strategies to address the global TB challenge necessitated the development of the post 2015 END TB strategy, approved to drive the elimination target of the disease by 2035 [2]. It has four principles and three pillars developed to reduce TB death, incidence and catastrophic cost [2].

The key component of the pillar one of the end TB strategy underpins early case detection as vital factor in TB dynamics [2]. Nigeria has adopted the END TB strategy however passive case finding method widely practiced has affected the case detection rate [21]. Consequently, a shift from passive to active case 
finding approach is crucial to improve TB case detection in Nigeria [24]. [25] maintained that adopting and implementing active case search as part of national policy is essential for finding missing cases of TB.

\subsection{Demographic and Geographical Context of Nigeria}

Nigeria is the most populous nation in Africa with a population 186 million and surface area of 923,768 square kilometers [26]. The country is divided into six geopolitical zones and has thirty-seven states, including the federal capital territory [27]. Nigeria's gross domestic product is 568,499 dollars and GDP per capita is 3203.2 [26]. The country shares borders with Benin, Ghana, Cameroun, and Chad. Nigeria is a multi-ethnic, multicultural and multilingual country; however English language remains the official language [27].

\subsection{Research Questions}

The FINER concept describes the characteristics of research question and comprises the following variables, ethical reflexion, originality, significance, practicability and importance of research to relevant to stakeholders [28] and [29].

More so, the PICOT concept explains the conceptual organization of the study with respect to methodology, target population, expected outcome and study period. In line with the FINER and PICOT principle and literature review of related studies, the following questions were selected [28] and [29]. The questions include:

1) How effective is contact tracing of index TB cases?

2) What are major determinants or predictors of $T B$ infection?

3) What is the HIV yield?

\subsection{Research Objectives}

The research objectives consist:

1) Determining presumptive $\mathrm{TB}$ cases among $\mathrm{TB}$ contacts in Abia State between $1^{\text {st }}$ October 2016-31 $1^{\text {st }}$ December 2016

2) Ascertaining the effectiveness of contact tracing of index TB cases in Abia State between $1^{\text {st }}$ October 2016-31 $1^{\text {st }}$ December 2016

3) Determining the HIV Status of TB contacts in Abia State between $1^{\text {st }}$ October 2016-31 $1^{\text {st }}$ December 2016.

4) Predictors of $\mathrm{TB}$ transmission among contacts of $\mathrm{TB}$ cases registered between $1^{\text {st }}$ October 2016-31 ${ }^{\text {st }}$ December 2016.

\section{Literature Review}

The chapter reviewed literatures related to contact tracing of infectious TB cases. The areas for review in relation to the past literatures were, biology, Transmission, diagnosis, treatment, prevention, epidemiology of tuberculosis and factors influencing TB transmission. More so there was a review of knowledge, practice and impact of contact tracing of pulmonary TB cases. 


\subsection{Biology of Tuberculosis}

Tuberculosis is a chronic disease caused by mycobacterium complex comprising mycobacterium tuberculosis, africanus, bovis, caprea pinnepedi and microti [30]. Mycobacterium bacterium is the etiologic agent for man. It is a gram-positive organism with inherent characteristics of dormancy, cellular pathogenicity, genetic similarities and cell wall complexity [31]. The dormancy of the organism in the cells and tissue is a function of the stable body immune system. In case of immunosuppression by disease, age and chronic disease like diabetes, the organism has the capacity to reactivate and progress from latent infection to active TB disease [31].

It is a slow growing organism with 12 - 24-hour multiplication time under favorable conditions [32]. The cell wall characteristics of the organism provides extraordinary impervious barrier to conventional antibiotics and contributes significantly to the virulence and longevity of the organism. [32] and [31]. The complexities of the cell wall and production of mycolic and arabinogalactan strengthens the virulence of the organism and production of these substances are inhibited by two most potent anti-drugs (Isoniazid and rifampicin) used in TB treatment [32]. According to [33], the survival and persistence of mycobacterium tuberculosis are enhanced by biotin synthesis.

More so, the pathogenicity is enhanced by catalase peroxidase that inhibits reactive oxygen produced by phagocytes (mce) and sigma factor that causes attenuation, mutation as well as drug resistance [31] and [34]. The synthesis of Phagocytes and phagolysosomes are integral part of body immune response however inherent pathogenic characteristics of mycobacterium to inhibit the fusion of phagosome and lysosomes is responsible for perpetuity of the organism in the tissue [35].

\subsection{Transmission of Tuberculosis}

Tuberculosis is an infectious disease transmitted by inhalation of droplet nuclei from an infectious TB case when he coughs, sneezes or sings [36]. The concept of epidemiological triangle provides basic principle for infection of disease [37]. The epidemiological triangle comprises of vertices, the agent or microbes that causes infection, the host is the reservoir of the disease while the environment are external factors that influence disease transmission [37]. The maintenance of equilibrium between the agent, host and environment is responsible for disease transmission as noted in Figure 1 [38]. Man (host) is the reservoir of mycobacterium tuberculosis (agent) and under poorly ventilated environment can result to $\mathrm{TB}$ infection and active disease [37]. The environment describes sociocultural and environmental factors that influence TB transmission. [37] opines that disrupting the equilibrium of the epidemiological triangle is the fulcrum for disease control.

Prolonged presence of undiagnosed cases in the community is key in TB transmission and epidemiology [39]. Low knowledge, poor health seeking behavior, inadequate diagnosing capacity and stigmatization are factors that impede early case detection [16]. 


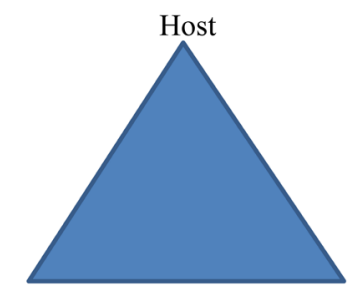

Agent

Environment

Figure 1. Adapted from Lee et al. (2003).

The rate of transmission is influenced by duration of contact with index case and status of body immune system consequently there are two related TB conditions, the latent TB infection and active TB disease [40]. The latent TB case is a situation where an individual is infected with TB bacilli but without symptoms of TB while an active TB case has perceptible symptoms of TB [40]. According to [36], it is estimated that one third of world population have latent TB and persons with $\mathrm{TB}$ infection has $10 \%$ risk of developing tuberculosis. There are medical and social factors that influence development or progression of latent TB to TB disease, these include HIV infection, Diabetes mellitus, Overcrowding, poor nutrition, intake of cytotoxic drugs and presence of index TB case [36]. HIV infection has been implicated as one of the diseases that drives the incidence and prevalence of TB.

A HIV patient has 20 - 30 risk of developing TB in his life time than HIV negative individuals (WHO, 2017b). The symptoms of TB include, persistent cough lasting for more than two weeks, night sweat, low grade fever, weight loss and hemoptysis [36]. The productive age group, children below 14 years and smokers are more affected than other population [36]. The Hospital environment is a risk site for transmission of TB especially among people living with HIV [39]. Consequently, implementing WHO 3Is (intensified case finding, infection control and isoniazid preventive therapy is vital for reducing nosocomial infection [41].

\subsection{Diagnosis of Tuberculosis}

Presumptive TB case is a person with symptoms of TB (cough lasting for more than two weeks) that is indicative of TB [42]. Diagnosis of tuberculosis clinically by doctors is challenging and often difficult, consequently laboratory investigations are essential in establishing definite diagnosis [43]. The novel work of Robert Koch in the 19th Century heralded the use of scientific laboratory techniques in diagnosing bacterial infections [44].

Several scientific methods are used in the diagnosis of TB. These include, sputum smear microscopy by Ziehl-Neelson technique for acid fast bacilli, rapid Xpert/MTB assay, line probe assay and sputum culture which is the gold standard but has limitation of prolonged turn-around time [45] and [46]. Chest $\mathrm{X}$-ray is primary tool for diagnosis of TB however, there is no radiological finding that pathognomonic of TB but may provide necessary clue for management 
and monitoring [43].

\subsection{Treatment of Tuberculosis}

A confirmed TB case is treated for six months using six months combined regimen. The regiment comprises of two months of intensive phase using four drugs (Isoniazid, Pyrazinamide, Ethambutol and Rifampicin and four months continuation phase using two drugs, Isoniazid and ethambutol [36] and [47]. The TB control program practices direct observed treatment (DOT) which ensures that patients takes his or her drugs under supervision by the health worker [48]. There is clinical and laboratory monitoring of the patients throughout the treatment, the outcome of the treatment at the end of six months could be cured, treatment failure, treatment completed or death [49].

\subsection{Prevention of Tuberculosis}

The four stages of disease prevention include primordial, primary, secondary and tertiary stages of prevention [3]. The primordial prevention targets disease determinants to reduce risk and exposure to risk. This can be achieved by improving socioeconomic status of the populace, HIV prevention and isoniazid prevention therapy for people living with HIV [50]. The primary prevention averts disease onset through behavior modification and enhancing resistance via vaccination [3]. The Bacillus Calmette-Guerin vaccine (BCG) is given at birth, though it has limited immunity but prevent the child from having a severe form of TB [51].

Apart from BCG there is no effective TB vaccine for TB in adults [52]. Secondary prevention entails screening, detecting and managing sub-clinical conditions to stop the progression of the disease [3]. This is achieved by early case detection through active case search and prompt treatment [48]. Tertiary prevention tends to reduce the impact of the disease condition by use of chemotherapy and socioeconomic rehabilitation [3].

\subsection{Epidemiology of Tuberculosis}

Globally', there are 10.4 million estimated cases of TB, 5.9 million were men while 3.5 million were women however 1.2 million were co-infected with TB/HIV in 2015 [53]. Among the high burden TB countries, Nigeria occupy the $4^{\text {th }}$ position and the death rate among HIV positive cases, children, adults has remained high [53]. Moreover, the emergence of drug resistant Tuberculosis (DR-TB) is worsening the effort made in control of TB [54]. DR-TB results when the mycobacterium TB bacilli develop resistant to conventional first line drugs used in the management of TB due to poor management of susceptible TB or inhalation of resistant strain from a DR-TB patient [54].

The major challenge impeding the control of and prolonged transmission of TB in the community is low and late detection of TB cases. In line with End TB strategy targets $90 \%$ of TB cases are projected to be notified and successfully 
treated. Globally, the case detection rate stands at $59 \%$ and $47 \%$ in sub-Saharan Africa which is below the expected targets [55]. Similarly, as noted by 2016 tuberculosis report there is 4.3 million gap between incident and notified cases [54]. In $2015,90,584$ cases of TB were detected in the country which is below the expected 586,000 target and this connotes a case detection rate of 15\% [54] and [55].

Moreover, the 2012 National prevalence study revealed an occurrence of 318 cases of TB per 100,000 population while the notified cases in $2015(90,584)$ translates to 55 cases per 100,000 population with deficit ratio of 5.8 [56] and [54]. The case-finding for Nigeria has remained abysmally low despite adoption and implementation the dot and stop TB strategies [13] and [23]. Low case detection is a global challenge and leads to prolonged transmission of TB as one infectious TB case has a potential to infect 10 - 15 persons annually [14].

Many factors such as poor access, stigmatization, inadequate human resources and insufficient direct observed treatment and diagnostic centers has been implicated as main causes of low case detection [16]. In-addition, [18] opined that TB case detection is affected by limitation of Ziehl-neelson techniques as $50 \%$ of the cases are miised. More so, [19] noted that TB case detection in Nigeria has been suboptimal stressing that low awareness has been a complementary contributing factor.

Furthermore, according to [57] poor knowledge of TB in community is a setback to presumptive TB case referral and early case detection. The case detection approach in Nigeria and most high burden countries is passive this is affected by low knowledge and poor health seeking behavior [21]. The key component of the pillar one of the end TB strategy underpins early case detection as vital factor in TB dynamics [2]. Therefore, changing the passive case finding methodology to dynamic case detection strategy is crucial to improving TB case detection in Nigeria [24]. The contacts of infectious TB cases are predictors of TB transmission [58]. Tracking of contacts of TB cases in the community might be a complementary approach in detecting missing cases of TB [59].

\subsection{Social Determinants of Health and Tuberculosis}

The ecological concept of health represents the relationship between man and environment with respect to disease causality. The socioeconomic and cultural determinants are upstream intricate factors and multifaceted dynamics that affect the population health [60] and [59]. The interplay of factors such as, poverty, population density, socioeconomic status, incarceration, stigmatization, poor nutrition and HIV infection are structural drivers of TB epidemic [61] [62].

Canadian Institute for Health Information [63] posits that basic drivers of TB epidemic are responsible for approximately $50 \%$ of population health. The economic status of every nation influences population health consequently community health trails a social gradient [64]. However according to [65] primordial disease prevention and health promotion tend to ascertain, resolve social and ecological factors that influence human health. 


\subsection{TB Case Finding in Nigeria}

Nigeria is a high burden country with low case detection rate of $15 \%$ [53]. The case finding approach in Nigeria similar to high burden countries has been passive [21]. The passive case finding is a proven means of case detection, but it is primarily influenced by poor access, socioeconomic status and might be responsible to low cases notification in Nigeria [22] and [66]. A shift from passive to intensified approach is necessary for improved case notification in Nigeria [48]

\subsection{Knowledge of Contact Tracing}

Close proximity to infectious TB disease is key in TB transmission and infection [58]. Related published studies on contact tracing underpin the fact that contact tracking is an active method of detecting supplementary cases. [67] conducted a study on awareness and practicality of contact tracing among patients in DOTs facilities in South eastern part of Nigeria and found that there was a poor understanding of contact tracing among patients in south East Nigeria; approximately two-thirds of participants reported no knowledge whatsoever of contact tracing. [68] reported similar findings in their qualitative study in Botswana. More specifically, they found that knowledge, practice and attitude were major impediments to patient contact tracing.

In a related interventional health education study on contact tracing by [69] revealed poor knowledge of contact tracing for both the study and control group. According to the study the pre and post intervention results were statistically significant which implies that educating of health workers on contact tracing will improve skills and case notification.

\section{Practice and Impact of Contact Tracing}

[4] conducted a study in Ethiopia in a population with high burden of TB. The objective of the study was to ascertain the proportion of TB cases among contacts and the effect of the strategy on case detection rate. Findings revealed 6-fold increment in notified cases and recommend retrospective contact tracing as useful strategy for active case finding. More so the study posited that period of exposure were major drivers of TB transmission among contacts. The study explained some terminologies and definitions, such as index TB case and contacts. An index TB case was defined as a confirmed case of TB with positive smear result using Ziehl-neelson technique, A Contact was defined as a person that have stayed with an index case over a period of three months before diagnosis.

Similarly a retrospective quasi-experimental cluster randomized design study among household and neighborhood contacts was conducted by [70] to ascertain the effectiveness of contact tracing to TB case-finding. The study is a qualitative study with intervention and control group using Xpert/MTB-RIF assay. The findings revealed a significant increase in number of cases detected in the intervention areas when compared to control areas, this underpins the significant of contact tracing process in TB case detection. [70] conducted a study on the impact of contact tracing of $\mathrm{TB}$ case detection and opined that contact tracing is a 
comprehensive and strategic method of finding missing cases of TB.

This was consistent with the retrospective study of [71] on contact tracing of contacts in workplace and among immigrants. The study yielded cases of TB and maintained that TB transmission can occur in workplace especially where immigrants from high burden countries are employed. The study suggested screening of immigrants for TB before employment. Furthermore, [72] conducted a study to determine how to improve TB contact tracing in Portugal by including close contacts and workplace contacts. The study systematically analyzed latent and active cases per index case, the findings discovered that conducting contact tracing in the homes and workplace produced more TB cases than passive approach. This implies that contact tracing produces more cases of TB than conventional passive process.

Furthermore, [70] conducted a prospective study on contact tracking of pediatric index cases using qualitative and quantitative methodology. The respondents were selected based on standard definitions of terms. The findings show that among caregivers screened, $63 \%$ were HIV positive and $4 \%$ were $\mathrm{TB}$ cases, while the household contacts yielded $3 \%$ cases of TB and $16 \%$ of HIV positive cases. The study suggested inclusion of adult and pediatric index cases as well as HIV screening during contact screening of TB index cases. Similarly, [74] comparative meta-analysis study among migrants revealed high $\mathrm{TB}$ cases among immigrants than local residents. However, the TB cases detected between the immigrants and general population were not statistically significant. The finding is similar to other studies that underpin high prevalence of TB among immigrants from high burden countries.

In a related longitudinal quantitative prospective study conducted by [75] in Peru among TB cases registered between March 2010 and November 2011, the result showed a high yield of presumptive ant confirmed TB cases. According to [75] key determinants such contacts, age sex and duration of exposure influenced TB transmission. He concluded that contact tracing is effective and determinants drives infection rate. In a different perspective [76] conducted a study in rural Malawi to assess contacts as determinants of TB transmission. The study is a case control study that combined contact tracing of TB and HIV. The finding revealed yield of $27 \mathrm{HIV}$ cases and 2 TB cases while 10 were enrolled into care which buttress the fact that mutual contact tracing for TB/HIV will enhance TB/HIV collaboration.

[17] piloted a study on impact of contact tracking of pediatric TB index cases in Gaborone, Botswana. A quantitative cross sectional descriptive study analyzed with STATA 12.0 version. The study revealed that among the $548 \mathrm{~TB}$ cases less than 15 years, $2.2 \%$ (12) were TB cases while $2 \%$ (11) were bacteriologically confirmed. This study-maintained similarity in the TB yield between pediatric and index adult TB cases contacts traced. More so, the study upheld that $59 \%$ of infection occur between one to six months before diagnosis.

In a comparable study by [49] on time of TB infection and effectiveness of household contacts using agent-based stimulation framework posits over $75 \%$ of 
infection happens before diagnosis and contact tracing can reduce TB incidence. Another study by [77] on contact tracking of pediatric index TB cases in United State of America from 2003 to 2012 revealed additional 532 (0.6\%) cases of TB from 84,998 presumptive TB cases screened while 15,411 (18.1\%) were latent TB cases. Further study conducted by [1] from 2013 to 2014 of newly detected TB cases yielded $4.51 \%$ of TB cases from 133 presumptive TB cases screened.

\subsection{The Conceptual Framework}

Theories are integral part of research dynamics as it provides suitable platform for designing research methodology and answering research question. [49] used agent-based stimulus theory to ascertain the timing of TB Transmission and influence on house hold contacts. [78] used contact tracing process model to determine the additional TB and HIV cases from tracking of infectious TB cases as noted in Figure 2 and will be applied in this study.

\section{Methodology}

\subsection{Research Methodology}

The research methodology, data collection and analysis are influenced by selection of appropriate paradigms [79]. The credibility of a positivist paradigm is predicated on the application of empirical and proven scientific approach [79] and [80]. The quantitative methodology was used and provided basis for data collection method and analysis [80]. The quantitative methodology introduces validity, reliability and credibility as it apply unbiased approach to unpack relationships between variables [79].

The retrospective cross sectional approach was applied by [4] while [72] used quantitative retrospective cross sectional study. Interventional methodology with quantitative arm was used by, [49] while longitudinal prospective approach was adopted by [75]. [81] used quasi-experimental retrospective study to examine the yield of contact tracing using two standard definitions for contact of index TB case. Furthermore, [74] adopted a comparative meta-analysis of published articles

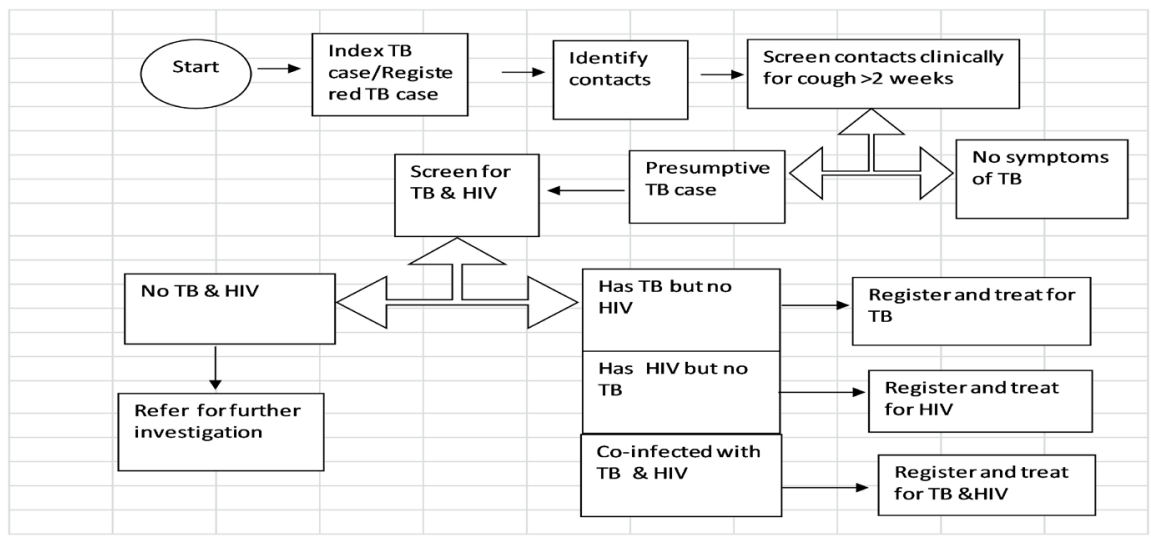

Figure 2. Contact tracing process model adapted from [78]. 
and studies to unravel the effectiveness of contact tracing among immigrant.

\subsection{Linking Methodology to Research Questions}

The quasi experimental study is between cross sectional observational and experimental design. However, the aims and objectives of the study influences the selection of research design and methodology. The selected design and quantitative methodology will answer the research questions. The quasi-experimental method is a non-randomized approach used when experimental design is not feasible and mostly applied in clinical research to measure impact [82]. The design applies statistical testing of selected study and control groups without random sampling [82].

The parameter for measuring quasi-experimental design is effectiveness [83].

The research was conducted in six directly observed treatment (DOT) facilities for the study group in the three senatorial zones of Abia State. Abia State is one of the States in the South Eastern region of Nigeria. The control group was also selected from six adjoining DOT facilities. Training was conducted for the control group but without intervention. Three urban and three rural DOT centers were selected for both the study and control group respectively. The questionnaire was pre-tested in one facility before using it for other facilities. Prior to the commencement of the intervention the baseline data was collected with the questionnaire.

The contacts of index TB cases notified from $1^{\text {st }}$ Octobers 2016 and $31^{\text {st }}$ December 2016 were traced and screened for TB using acid fast bacilli test or xpert/MTB-RIF assay. The respondents were also screened for HIV in line with the national algorithm. The research assistance selected from the designated facilities, were trained and supported to track the enrolled cases. The sputum samples of presumptive cases were transported by the research assistance to selected laboratories for examination. The already existing National TB forms and registers were used for documentation.

\subsection{Research Hypothesis}

The research hypothesis states that "tracing and examining contacts of index or infectious TB cases is an effective method of detecting cases of TB" while null hypothesis opines that "tracing and examining contacts of index or infectious $\mathrm{TB}$ cases is not an effective method of detecting cases of TB". Subjecting the hypothesis to statistical testing will define the impact of the intervention [84].

The data collection plan produces roadmap for adopting hypothesis, sample size calculation, designing of questionnaire and data storage. In quantitative study, different data collection techniques are applied.

These include administering of questionnaire, recording observed events and clinical trials. A structured interviewer administered questionnaire was used (Annex 1.4). Information collected were socio-demographic variables, including personal data, medical history, family disease history and marital status. English language will be used and Ibo for those who do not understand English. The 
questionnaire consists of the following sections: Screening for Contacts, diagnosis of Tuberculosis and HIV and summary of data from facility and state TB program. Prior to commencement of study the questionnaire was pre-tested in selected DOT centers. There was training of the research assistance on tools for data collection, ethical issues and data entry. The collected data was entered into a excel sheet, cleaned and coded before analyzing with SPSS.

\subsection{Target Population}

All index TB or pulmonary cases of Tuberculosis diagnosed and registered in the National TB program.

\subsection{Study Period}

The study was conducted between $1^{\text {st }}$ October 2016-31 ${ }^{\text {st }}$ December 2016.

\subsection{Sample Size}

To ensure credible result in quantitative study, determining adequate sample size is mandatory. A study conducted by [85] applied this formula to ascertain the sample size for comparing the study and control group in quasi-experimental study. The formula was adopted in this study.

The formula is $2 \mathrm{SD}^{2}\left(\mathrm{Z}_{\infty / 2}+\mathrm{Z}_{\hat{\mathrm{a}}}\right)^{2} / \mathrm{D}^{2}[85]$

$\mathrm{Z}_{\infty / 2}$ is the normal standard deviation which corresponds to 1.96 at $95 \%$ confidence interval.

$Z_{\hat{a}}$ represents power and is usually 0.84 at $80 \%$ power.

$\mathrm{SD}$ is the standard deviation from related studies.

$\mathrm{D}$ is the effect size it is usually 5 percent or 0.05

A quasi experimental study to ascertain the impact of contact tracing of index TB cases by [81] yielded $2.7 \%$ increase at $95 \%$ standard deviation. Consequently, calculating the sample size with the formula equals,

$2 \times(1.96)^{2} \times(1.95+0.84)^{2} / 0.05=120$. This implies that 120 index TB will be recruited for the study and control group respectively.

\subsection{Aligning Data Collection, Analysis to Methodology and Research Questions}

Aligning data collection technique as well as analysis to methodology will elucidate the research questions and objective of the study. The collected data provides information for addressing the research questions. The success of the intervention was determined by the analysis of the post intervention data. The analysis involved description of demographic data for index and contacts of TB cases. Further analysis produced the frequencies and proportion of HIV among index cases and contacts. The mean or median may be applied to compare means between the intervention and control group. Multiple regressions were applied to predict the value of the dependent variable based of significance of independent variables [86].

In this study we wish to ascertain if $\mathrm{TB}$ transmission is predicted based on age, 
sex, occupation, educational status, monthly income, rural-urban dwelling, DM, duration with index TB case and being a presumptive TB case. The data was analyzed without violation of basic assumptions such as (the data must be continuous dependent variable, no significant outliers, multicollinearity, homoscedasticity, must be more than two independent variables and residual errors are normally distributed [86]. The following indicators were used by [74] in their meta-analysis study to ascertain the effectiveness of contact tracing among immigrants as noted in Table 1.

TB yield: measures the proportion of cases of TB among contacts.

Contact-index case ratio: measures the proportion of screened contacts relative to index case.

Coverage: measures the proportion of contacts screened examined relative to those examined.

Latent TB yield: measures the percentage of TB cases proportionate to Contacts.

Presumptive TB yield: measures the number of TB contacts with signs and symptoms of TB. The above indicators were adopted to measure the effectiveness of contact tracking of index cases in this study.

The indicators were used to assess the impact of the study by comparing the post intervention data with the baseline data. The post-implementation data of q4 2016 will be compared to pre-implementation data of q3 2016. The chi square analysis demonstrated the association of variables while the regression analysis will determine the predictors of TB transmission.

\subsection{Ethical Considerations}

The experimental studies and studies involving human participation or use of personal data and samples have high level of ethical risks [83]. The level of risk and adverse effect of the study was defined and confidentiality assured [83]. The respondents were adequately compensated and given an opportunity to withdraw without any consequence [83] and [87]. The inform consent form was fully explained and the participants voluntarily signed before the questionnaire was administered.

\section{Findings}

\subsection{Index TB Cases}

The study is aimed at establishing the effectiveness and impact of contact tracing of index TB cases, the predictors of transmission and HIV yields among contacts. A total of 168 index cases of TB were recruited in the study registered in the intervention facilities while 162 were recruited in the control facilities. Furthermore, out of 168 index TB visited by the research team, $301 \mathrm{~TB}$ contacts were identified. Among the identified index cases, 81.7\% were greater than 15 years while $18.3 \%$ were less than 15 years. More so, 54 (18\%) of the index TB cases were HIV positive while (247) $82 \%$ were HIV negative. The detailed information of the index TB cases including socio-demographic data is shown in Table 2. 
Table 1. Was adopted by [74] for measuring effectiveness.

\begin{tabular}{lcccc}
\hline Group/data & $\begin{array}{c}\text { Coverage } \\
(\%)\end{array}$ & $\begin{array}{c}\text { Contact index } \\
\text { ratio }\end{array}$ & $\begin{array}{c}\text { Presumptive } \\
\text { TB yield }\end{array}$ & $\begin{array}{c}\text { TB yield } \\
\text { registered in the } \\
\text { State }\end{array}$ \\
\hline $\begin{array}{l}\text { Pre-implementation } \\
\text { data }\end{array}$ \\
Intervention group \\
Control group \\
Post-intervention \\
$\quad$ data
\end{tabular}

Table 2. Socio-demographic data of index TB cases.

\begin{tabular}{|c|c|c|}
\hline Index TB cases (168) & Frequency & Percentage (\%) \\
\hline \multicolumn{3}{|c|}{ SEX } \\
\hline Males & 118 & $70.20 \%$ \\
\hline Females & 50 & $29.80 \%$ \\
\hline \multicolumn{3}{|l|}{ Age } \\
\hline$<15$ years & 6 & $3.6 \%$ \\
\hline 16 - 40 years & 96 & $57.10 \%$ \\
\hline $41-61$ years & 50 & $29.80 \%$ \\
\hline Above 60 years & 16 & $9.50 \%$ \\
\hline \multicolumn{3}{|l|}{ MARITAL STATUS } \\
\hline Single & 103 & $61.30 \%$ \\
\hline Married & 48 & $28.60 \%$ \\
\hline Divorced & 3 & $1.80 \%$ \\
\hline Widowed & 5 & $3.00 \%$ \\
\hline Polygamous & 9 & $5.40 \%$ \\
\hline \multicolumn{3}{|l|}{ TRIBE } \\
\hline Ibos & 168 & $100 \%$ \\
\hline Hausa & 0 & $0 \%$ \\
\hline Yoruba & 0 & $0 \%$ \\
\hline \multicolumn{3}{|l|}{ EDUCATIONAL QUALIFICATION } \\
\hline Primary & 60 & $34.70 \%$ \\
\hline Secondary & 91 & $52.60 \%$ \\
\hline Tertiary & 17 & $9.80 \%$ \\
\hline \multicolumn{3}{|l|}{ ASSOCIATED RISK FACTORS } \\
\hline No associated risk factor & 156 & $90.20 \%$ \\
\hline Drug addict & 2 & $1.20 \%$ \\
\hline Pregnancy & 5 & $2.90 \%$ \\
\hline Alcholics & 5 & $2.90 \%$ \\
\hline
\end{tabular}




\section{Continued}

AGE DISEASE WAS DIAGNOSED

$\begin{array}{ccc}<15 \text { years } & 6 & 3.6 \\ 16 \text { - } 40 \text { years } & 96 & 57.10 \% \\ 41-61 \text { years } & 50 & 29.80 \% \\ \text { Above } 60 \text { years } & 16 & 9.50 \%\end{array}$

INDEX CASES PLACED ON ANTI TB DRUGS

$\begin{array}{lcc}\text { Placed on TB drugs } & 168 & 100 \% \\ \text { Not placed on drugs } & 0 & 0 \%\end{array}$

LIVING APARTMENT OF INDEX TB CASES

$\begin{array}{lcc}\text { 1 room apartment } & 6 & 3.50 \% \\ \text { 2 room apartment } & 96 & 55.50 \% \\ 3 \text { room apartment } & 50 & 28.90 \% \\ 4 \text { room apartment } & 16 & 9.20 \% \\ 5 \text { room apartment } & 5 & 2.90 \%\end{array}$

OCCUPATION

$\begin{array}{ccc}\text { Unemployed } & 67 & 39.88 \% \\ \text { Public servant } & 78 & 46.43 \% \\ \text { Farming } & 16 & 9.52 \% \\ \text { Trading } & 7 & 4.17 \% \\ \text { Skilled artisans } & 0 & 0 \% \\ \text { Student } & 0 & 0 \% \\ \text { Health worker } & 0 & 0 \% \\ \text { Community leader } & 0 & 0 \% \\ \text { Retiree } & 0 & 0 \%\end{array}$

MONTHLY INCOME (Naira)

$\begin{array}{ccc}18,000 & 67 & 39.88 \% \\ 19,000-50,000 & 78 & 46.43 \% \\ 51,000-99,000 & 16 & 9.52 \% \\ >100,000 & 7 & 4.17 \%\end{array}$

BCG VACCINATION

Vaccinated at birth $\quad 164 \quad 97.62 \%$

Not vaccinated at birth $\quad 4 \quad 2.38 \%$

PERIOD INDEX CASES SPENT WITH CONTACTS

$\begin{array}{ccc}\text { less than three months } & 12 & 7 \% \\ 3 \text { - } 6 \text { months } & 24 & 14 \% \\ 7 \text { - 12 months } & 36 & 22 \% \\ >1 \text { year } & 96 & 57 \%\end{array}$




\subsection{Contacts of Index TB Cases}

A total of 301 contacts were identified during the process, 176 (58.5\%) were males while 125 (41.5\%) were females. All the contacts (100\%) had contacts with index TB cases. Amid the TB contacts 55 (18.3\%) were below 15years, 209 (69.4\%) were between 16 - 45 years while $36(12.0 \%)$ were $>46$ years. 98 (32.6\%) were rural dwellers while 203 (67.4) were urban dwellers. 44 (14\%) of the TB contacts had no basic qualification, 140 (45.9\%), had first school leaving certificate, $93(30.9 \%)$ were graduates from tertiary institutions while 23 (7.6) had master degree in various disciplines. However, 59 (19.6\%) of the TB contacts were civil servants, 9 (3\%) were students, $112(37.2 \%)$ were traders, $112(37.2 \%)$ were farmers, while 9 (3\%) were artisans. 299 (99.3\%) were not diabetic while 2 (0.7\%) had Diabetes Mellitus.

Furthermore, 180 (59.8\%), of the contacts collect below 18,000 Naira as their monthly income, 108 (36.2\%), receive between 19,000 to 40,000 Naira, 11 (3.7\%) collect 41,000 to 60,000 Naira and 1 (3\%) receive 61,000 to 80,000 and above Naira. $171(56.8 \%)$ had no symptoms and signs of TB while 130 (43.2\%) were presumptive TB cases. The presumptive cases were screened for Xpert MB/Rif assay and AFB microscopy. Among the presumptive TB cases screened, 68 were confirmed TB case which is $22.6 \%$ of all the identified contacts and $52 \%$ of presumptive TB cases; however, $77.4 \%$ of the contacts had no TB. More so, 297 (98.7\%) of the TB contacts had BCG vaccination while 4 (1.3\%) were not vaccinated.

Screening of the contacts HIV showed that $4.3 \%$ were HIV positive while 95.7\% were HIV negative however $1.2 \%$ were co-infected with TB and HIV. 17\% of the 68 cases were from rural facilities while $51 \%$ were from urban facilities. There was $100 \%$ coverage for the intervention and control areas. The pre-implementation TB cases registered in the intervention and control areas were 187 and 162 respectively. The total cases registered in the state in that quarter were 336 . The contact/index ratio for the intervention area is $55 \%$, presumptive TB yield $130(43.2 \%)$ of the total contacts examined and TB yield 68 (22.6\%).

Since no intervention happened in the control areas apart from training and collection of data, there were no contact/index ratio, presumptive TB yield or confirmed cases of TB consequently the total cases registered in the area remained the same. The total TB cases in the intervention increased from 187 to 255 while the total cases detected in the State increased to from 336 to 417 which signify 24 percent change as indicated in Table 3 . The paired sample TB test comparing the pre-implementation data 336 and post-implementation data 417 was statistically significant $(\mathrm{p}<0.00)$.

The Chi-square test or Pearson's chi-square test was used to test the association between categorical variables (independent and dependent variables). The two assumptions of analyzing categorical numerical variables and having more than one independent categorical variables were not violated. The result of the 
chi square test in Table 4 shows that education, HIV Status and presumptive TB case were statistically significant, sex and age were close to significant while others variables were not significant. Further, Chi square analysis shows that 163 (95.3\%) of non-presumptive TB cases never developed TB while 8 (4.7\%) developed TB.

However, for presumptive TB cases, $70(53.8 \%)$ had no chance of developing TB while 60 (46.2\%) developed TB. 229 (71.1\%) TB contacts with BCG vaccination did not develop TB while $22.9 \%$ developed TB. More so, among unvaccinated cases, $100 \%$ did not develop TB while $0 \%$ had zero chance of becoming a TB case. $74(80.4 \%)$ TB contacts without qualification had no TB while 18 (19.6\%) developed TB. 77 (82.8\%) of TB contacts with first school leaving certificate had no TB while 16 (17.2\%) had TB. 73 (78.5\%) graduates TB contacts did not develop TB while 20 (21.5\%) became TB cases. 9 (39.7\%) of TB contacts with master's degree had no chance of becoming a TB case while $14(60.9 \%)$ developed TB.

Multiple regression analysis was applied to identify predictors of TB transmission in the study area. The analysis ensured no violation of assumptions of linearity, normality, multicollinearity, homoscedasticity and no significant outliers. The 0.515 of the $\mathrm{R}$ depicts that the variables shows good level of prediction of a TB case. The $\mathrm{R}^{2}$ value shows that the independent variables account for $28.3 \%$ variability or prediction as indicated in Table 5 .

Table 6 of the multiple regression analysis test the good fit of the model to the data with respect to F-ratio. The data is statistically significant which shows a good prediction of the independent variables to a confirmed TB case. F $(11,288)$ $=10.337, \mathrm{p}<0.00$. This supports the assumption of homoscedasticity.

Table 3. Outcome of contact tracing intervention.

\begin{tabular}{lccc}
\hline & $\begin{array}{c}\text { Pre-implementation TB cases } \\
\text { registered q3 2016 }\end{array}$ & $\begin{array}{c}\text { Post-implementation TB cases } \\
\text { registered q4 2016 }\end{array}$ & $\begin{array}{c}\text { Percentage } \\
\text { Change }\end{array}$ \\
\hline TB cases registered & 336 & 417 & $24 \%$ \\
\hline
\end{tabular}

Table 4. Chi square test result.

\begin{tabular}{cccc}
\hline Chi square result & \multicolumn{3}{c}{ Cross tabulation of categorical variables with TB case } \\
\hline Categorical variables & $\begin{array}{c}\text { Pearson chi-square } \\
\text { (value) }\end{array}$ & df & $\begin{array}{c}\text { Asymp. Sign. Two sided } \\
\text { (p-value) }\end{array}$ \\
\hline Sex & 2.94 & 1 & 0.087 \\
Age & 0.137 & 3 & 0.079 \\
Occupation & 3.118 & 4 & 0.538 \\
Education & 23.226 & 3 & 0.0001 \\
Monthly income & 1.663 & 3 & 0.645 \\
Rural Urban Dwelling & 0.0001 & 1 & 0.997 \\
Diabetes mellitus & 0.59 & 1 & 0.442
\end{tabular}




\section{Continued}

\begin{tabular}{cccc}
\hline Duration with index case & 3.546 & 3 & 0.315 \\
Presumptive TB case & 73.41 & 1 & 0.0001 \\
HIV status & 4.227 & 1 & 0.039 \\
BCG vaccination & 1.188 & 1 & 0.276 \\
\hline
\end{tabular}

Table 5. Model summary of multiple regression analysis.

\begin{tabular}{ccccc}
\hline & R & R SQUARE & $\begin{array}{c}\text { ADJUSTED R } \\
\text { SQUARE }\end{array}$ & Standard Error of the Estimate \\
\hline 1 & $0.532^{\mathrm{a}}$ & 0.283 & 0.256 & 0.362 \\
\hline
\end{tabular}

Table 6. Multiple regression analysis of various variables.

\begin{tabular}{cccccc}
\hline \multirow{2}{*}{ Model } & \multicolumn{2}{c}{$\begin{array}{c}\text { Unstandardized } \\
\text { Coefficients }\end{array}$} & $\begin{array}{c}\text { Standardized } \\
\text { Coefficients }\end{array}$ & t & Sig. \\
\cline { 2 - 3 } & B & Std. Error & Beta & & \\
\hline (Constant) & 1.093 & 0.382 & & 2.865 & 0.004 \\
SEX & -0.07 & 0.044 & -0.082 & -1.599 & 0.111 \\
AGE & 0.036 & 0.039 & 0.047 & 0.933 & 0.352 \\
OCCUP & -0.028 & 0.019 & -0.077 & -1.52 & 0.13 \\
EDUSTATUS & 0.014 & 0.024 & 0.032 & 0.606 & 0.545 \\
MONTHLYINCOM & -0.034 & 0.036 & -0.047 & -0.944 & 0.346 \\
RURURBAN & -0.015 & 0.045 & -0.017 & -0.326 & 0.745 \\
DM & -0.071 & 0.26 & -0.014 & -0.272 & 0.786 \\
Duration with index case & 0.006 & 0.019 & 0.018 & 0.346 & 0.729 \\
PRESUMPTIVETBCASE & 0.408 & 0.044 & 0.482 & 9.293 & 0 \\
HIVSTATU & 0.181 & 0.107 & 0.088 & 1.702 & 0.09 \\
BCGVACCINATION & -0.42 & 0.186 & -0.115 & -2.255 & 0.025 \\
\hline
\end{tabular}

Table 6 shows the predictors of TB transmission by the independent variables. The independent variables such as (occupation, duration of stay with index TB case, Sex, age, monthly income, rural urban dwelling, diabetic mellitus and educational status) were not good predictors of transmission of TB case as noted in Table 5 , since they were not statistically significant. Interestingly being a presumptive TB case, $(p=0.00)$ and BCG vaccination $(p=0.02)$ were statistically significant and good predictors of $\mathrm{TB}$ transmission. This supports the findings of the chi square test of presumptive $\mathrm{TB}$ case that was statistically significant.

\section{Discussion}

The study tends to ascertain the effectiveness of contact tracing of index TB case finding, the proportion of HIV cases among contacts of TB cases and predictors 
of TB transmission among the contacts. Low and late case reporting is a major challenge to TB case finding in Nigeria. Passive case approach is actually affecting the case detected within the National TB control program. The TB transmission dynamics will benefit immensely from comprehensive active case search. The coverage of $100 \%$ implies that all recruited cases in the study were screened and this assured validity as well as reliability of the study. The fifty-five percent contact/index ratio for the intervention area implies that all the contacts of index cases were fully investigated with respect to the identified contacts, this also guarantees sensitivity and reliability. There was a remarkable increase of both presumptive TB and confirmed TB cases in the intervention facilities than the control facilities. This supports the research hypothesis that tracing and examining contacts of index or infectious TB cases is an effective method of detecting cases of 'TB' thereby rejecting the null hypothesis that opines that tracing and examining contacts of index or infectious TB cases is not an effective method of detecting cases of TB'

The high yield of presumptive TB (43.2\%) and TB of $22.6 \%$ supports the theory that contact tracing of Tuberculosis cases increases case detection. The notified TB case increased from 336 to 417 in the intervention area within the specified period. This is consistent with other documented report that underpins that contact tracing yields additional cases of TB. The notified TB cases increase from 336 to 417 is statistically significant and signifies $24 \%$ change as noted in Table 3. A related study by [71] shows a yield of 5\% though low when compared to the study finding. Also, [75] study yielded 34\% of TB cases which is higher than $22.6 \%$ TB yield from the study.

A similar study by [77] produced $13.6 \%$ of TB cases which buttresses the fact that contact tracing is an effective means of finding new cases of TB. The findings and other documented studies illustrate that contact tracing of index TB cases is a complementary and effective means of finding undetected cases in both high and low burden countries. This novel finding should be prioritized in Nigeria with $17 \%$ case detection rate attributed by relying on passive case finding strategy. The chi square findings revealed that presumptive TB case and level of education influence becoming a TB case.

The second research questions intended to determine the predictors of TB transmission among contacts of index TB cases. Distinct socioeconomic and cultural factors influence the transmission of Tuberculosis. In addition to documented evidence of determinants of TB such as complexities of poverty, overcrowding, social inequality and Diabetes Mellitus, the findings of this study suggested that presumptive TB case and BCG vaccination were strong predictors of TB transmission.

The $4.3 \%$ yield of HIV cases supports and buttresses the interaction between $\mathrm{HIV}$ and TB, consequently screening of HIV among contacts of TB may boost detection of TB and HIV cases. More so TB/HIV collaboration during contact tracing of index cases is a positive step for finding HIV and TB cases. Similarly, 
in a study by [76] out of 267 index TB cases screened, 27 (10\%) were HIV cases which is consistent with the finding of $4.3 \%$. Further study by [73] generated $63 \%$ of HIV cases, though greater than study findings of $4.3 \%$ but authenticates the influence of HIV on TB transmission. This implies that integrating TB/HIV strategy during contact tracing of index is strongly recommended. However further studies is needed to ascertain the cost effectiveness of the process as well as the impact of the strategy among smear negative TB cases. Investigating contact tracing among smear positive cases is necessary as most smear negative TB cases are due to limitation of the Ziehl-neelson technique and not absence of transmissible bacilli in the lungs.

\subsection{Recommendations}

The essence of infection control is to eliminate and eradicate disease. In line with disease prevention strategies early case detection is one of the effective strategies for disease control. The study portrays that contact tracing of index TB cases is a complementary and effective means of detecting missing cases of Tuberculosis. Integrating the concept as part of routine $\mathrm{TB}$ strategic case finding activities in the National TB control program will improve TB cases detected in the country. This can be achieved by building the capacity of the National, State and general health care workers involved in TB control in Nigeria on contact tracing. Therefore, integrating active screening of patients visiting the general outpatient department in the hospital and active house to house search in the community will increase presumptive TB cases for laboratory screening. More so the country should support the implementation of contact tracing of index TB cases through bold policies and increasing budget for TB control. It is also imperative to effectively integrate $\mathrm{TB} / \mathrm{HIV}$ strategies during contact tracing.

\subsection{Study Limitations}

The study limitation describes the inherent characteristics of design and methodology that influence research findings. The quasi-experimental study is associated with non-sampling which affects internal analysis and internal validity. The sample size is limited and may not project the desired impact. As a result of retrospective data collection method adopted for the study there were missing and incomplete data which affected the data analysis. There were also longitudinal effects of time constraints due to restricted date of submission of the project. Cultural and data degradation biases during study design influenced the study. The transport cost of sending sputum samples to the AFB microscopy laboratory was much and there is need to examine the cost effectiveness of the study. More so the study did not consider other forms of Tuberculosis that are capable of transmitting tuberculosis.

\section{Conflicts of Interest}

The authors declare no conflicts of interest regarding the publication of this paper. 


\section{References}

[1] Gupta, M., Saibannavar, A.A. and Kumar, V. (2016) Household Symptomatic Contact Screening of Newly Diagnosed Sputum Smears Positive Tuberculosis Patients-An Effective Case Detection Tool. Lung India, 33, 159-162.

[2] WHO (2017) End TB Strategy. http://www.who.int/tb/post2015_strategy/en/

[3] AFMC (2013) Basic Concepts in Prevention, Surveillance, and Health Promotion. https://afmc.ca/pdf/AFMC-Primer-on-Population-Health-

[4] Gashu, Z., Jerene, D., Ensermu, M., Habte, D., Melese, M., Hiruy, N., Shibeshi, E., Hamusse, S.D., Nigussie, G., Girma, B., Kassie, Y., Haile, Y.K. and Suarez, P. (2016) The Yield of Community-Based Retrospective Tuberculosis Contact Investigation in a High Burden Setting in Ethiopia. PLoS ONE, 11, e0160514. https://doi.org/10.1371/journal.pone.0160514

[5] ISTC (2014) The Hague: TB Care. http://www.who.int/tb/publications/ISTC_3rdEd.pdf?ua=1

[6] Stapledon, R and Viney, K. (2010) Guidelines for Tuberculosis Contact Tracing in Pacific Island Countries and Territories.

https://www.spc.int/tb/en/publications/doc_download/2-tuberculosis-contact-traci ng-guide-

[7] Shah, S.A., Qayyum, S., Abro, R., Baig, S. and Creswell, J. (2013) Active Contact Investigation and Treatment Support: An Integrated Approach in Rural and Urban Sindh, Pakistan. The International Journal of Tuberculosis and Lung Disease, 17, 1569-1574. https://doi.org/10.5588/ijtld.13.0169

[8] Armbruster, B. and Brandeau, M.L. (2007) The Cost-Effectiveness of Contact Tracing for Endemic Diseases. http://users.iems.northwestern.edu/ armbruster/2007AugUBC_poster.pdf

[9] Yadav, R.P., Nishikiori, N., Satha, P., Eang, M.T. and Lubell, Y. (2014) Cost-Effectiveness of a Tuberculosis Active Case Finding Program Targeting Household and Neighborhood Contacts in Cambodia. The American Journal of Tropical Medicine and Hygiene, 90, 866-872. https://doi.org/10.4269/ajtmh.13-0419

[10] Firth, J. (2018) History of Tuberculosis. Part 1-Phthisis, Consumption and the White Plague. Journal of Military and Veterans, Health Issue, 22, No. 2.

[11] Beste, D.J. and McFadden, J. (2010) Systems Biology of the Metabolism of Mycobacterium tuberculosis. Biochemical Society Transactions, 38, 1286-1289. https://doi.org/10.1042/BST0381286

[12] CDC (2013) Ten Top Causes of Death in Nigeria. https://www.cdc.gov/globalhealth/countries/nigeria/why/default.htm

[13] WHO (2017) Stop TB Strategy. http://www.who.int/tb/strategy/stop_tb_strategy/en/

[14] WHO (2002) The World Health Report 2002: Reducing Risks, Promoting Healthy Life. http://www.who.int/whr/2002/en/whr02_en.pdf

[15] Ukwaja, K.N., Alobu, I., Ifebunandu, N.A., Osakwe, C. and Igwenyi, C. (2013) Trend in Case Detection Rate for All Tuberculosis Cases Notified in Ebonyi, Southeastern Nigeria during 1999-2009. The Pan African Medical Journal, 16, 11. https://doi.org/10.11604/pamj.2013.16.11.680

[16] Amenuvegbe, G.K., Francis, A. and Fred, B. (2016) Low Tuberculosis Case Detection: A Community and Health Facility Based Study of Contributory Factors in the Nkwanta South District of Ghana. BMC Research, 9, 330. 
https://doi.org/10.1186/s13104-016-2136-X

[17] Puryear, S., Seropola, G., Ho-Foster, A., Arscott-Mills, T., Mazhani, L., Firth, J., Goldfarb, D.M., Ncube, R., Bisson, G.P. and Steenhoff, A.P. (2013) Yield of Contact Tracing from Pediatric Tuberculosis Index Cases in Gaborone, Botswana. International Journal of Tuberculosis and Lung Disease, 17, 1049-1055.

https://doi.org/10.5588/ijtld.12.0933

[18] Ekundayo, E.O., Abbey, S.D. and Okorie, O. (2014) Case-Detection Rate of Direct Sputum Smear Microscopy for Diagnosis of Pulmonary Tuberculosis in Abia State, Nigeria. African Journal of Clinical and Experimental Microbiology, 15. https://doi.org/10.4314/ajcem.v15i2.9

[19] Okuonghae, D. and Omosigho, S. (2010) Determinants of TB Case Detection in Nigeria: A Survey. Global Journal of Health Science, 2, 123-128. https://doi.org/10.5539/gjhs.v2n2p123

[20] Olakunle, S.O., Olanrewaju, O., Olarewaju, A.O., Fasanmi, A. and Opara, U.R. (2016) Knowledge Gap about Tuberculosis Case Detection among Patent Medicine Vendors in Osogbo: Implications for Social Work. European Journal of Pharmaceutical and Medical Research, 3, 89-93.

[21] Ekundayo, E.O., Onuka, O., Mustapha, G. and Geoffrey, M. (2015) Active Case Finding of Pulmonary Tuberculosis among Prison Inmates in Aba Federal Prison, Abia State, Nigeria. Advances in Infectious Diseases, 5, 57-62. https://doi.org/10.4236/aid.2015.51006

[22] Ukwaja, K.N., Alobu, I. and Hopewell, P.C. (2013) Household Catastrophic Payments for Tuberculosis Care in Nigeria: Incidence, Determinants, and Policy Implications for Universal Health Coverage. Infectious Diseases of Poverty, 2, 21. https://doi.org/10.1186/2049-9957-2-21

[23] WHO (2008) TB. http://www.who.int/tb/publications/2008/who_htm_tb_2008_401_eng.pdf

[24] Markos, A., Mark, D., Liya, W., Abebech, D., Adane, M. and Howard, E. (2012) Case Detection: Can We Remain Passive While the Process Is Active. Pan African Medical Journal, 11, 50.

[25] Oshi, D.C., Chukwu, J.N., Meka, A.O., Madichie, N.O., Ogbudebe, C.L., Onyeonoro, U.U., Ikebudu, J.N., Ekeke, N., Anyim, M.C. and Aguwa, E.N. (2016) Does Intensified Case Finding Increase Tuberculosis Case Notification among Children in Resource-Poor Settings? A Report from Nigeria. International Journal of Mycobacteriology, 5, 44-50. https://doi.org/10.1016/j.ijmyco.2015.10.007

[26] UNDATA (2017) Nigeria Profile. http://data.un.org/CountryProfile.aspx?crName=Nigeria

[27] FGN (2014) The National Strategic Plan for Tuberculosis Control. https://www.medbox.org/nigeria/nigeria-the-national-strategic-plan-for-tuberculosi s-control-2015-2020/preview?q=

[28] Riva, J.J., Malik, K.M., Burnie, S.J. Endicott, A.R. and Busse, J.W. (2012) What Is Your Research Question? An Introduction to the PICOT Format for Clinicians. Journal of the Canadian Chiropractic Association, 56, 167-171. http://www.ncbi.nlm.nih.gov/pmc/articles/PMC3430448/

[29] Farrugia, P., Petrisor, B.A., Farrokhyar, F. and Bhandari, M. (2010) Research Questions, Hypotheses and Objectives. Canadian Journal of Surgery, 53, 278-281.

[30] Kolattukudy, P.E., Fernandes, N.D., Azad, A.K., Fitzmaurice, A.M. and Sirakova, T.D. (1997) Biochemistry and Molecular Genetics of Cell-Wall Lipid Biosynthesis in Mycobacteria. Molecular Microbiology, 24, 263-270. 
https://doi.org/10.1046/j.1365-2958.1997.3361705.x

[31] Wheeler, P.R. (1994) Metabolism of Mycobacterium tuberculosis. In: Bloom, B.R., Ed., Tuberculosis: Pathogenesis, Protection and Control, American Society for Microbiology Press, 353-385.

[32] Delogu, G., Sali, M. and Fadda, G. (2013) Biology of Mycobacterium Infection. Mediterranean Journal of Hematology and Infectious Diseases, 5, e2013070.

[33] Wilson, D.J., Dai, R., Nag, P.P., Liu, F., Boyce, P.J., Bittker, A.J., Schreiber, S.L., Finzel, B.C. and Schnappinger, D. (2015) Target-Based Identification of Whole-Cell Active Inhibitors of Biotin Biosynthesis in Mycobacterium tuberculosis. Chemistry and Biology, 22, 5-6.

[34] Niemann, S., Merker, M., Kohl, T. and Supply, P. (2016) Impact of Genetic Diversity on the Biology of Mycobacterium tuberculosis Complex Strains. Microbiology Spectrum, 4.

[35] Vergne, I., Chua, J., Singh, S.B. and Deretic, V. (2004) Cell Biology of Mycobacterium tuberculosis Phagosome. Annual Review of Cell and Developmental Biology, 20, 367-394. https://doi.org/10.1146/annurev.cellbio.20.010403.114015

[36] WHO (2017) Tuberculosis. http://www.who.int/mediacentre/factsheets/fs104/en/

[37] Lee, A. and Abdullah, A.S.M. (2003) Will the SARS Epidemic Recur? Host and Environment Are Key Factors, 57, 770-777.

[38] CDC (2012) Principles of Epidemiology in Public Health Practice, Third Edition: An Introduction to Applied Epidemiology and Biostatistics. https://www.cdc.gov/ophss/csels/dsepd/ss1978/lesson1/section8.html

[39] Kompala, T., Shenoi, S.V. and Friedland, G. (2013) 'Transmission of Tuberculosis in Resource-Limited Settings. Current HIVIAIDS Reports, 10, 264-272. https://doi.org/10.1007/s11904-013-0164-x

[40] CDC (2016) Latent TB Infection and TB Disease. http://www.cdc.gov/tb/topic/basics/tbinfectiondisease.htm

[41] WHO (2017) Scaling up the Three Is for TB/HIV. http://www.who.int/hiv/topics/tb/3is/en/

[42] WHO (2014) Definitions and Reporting Framework for Tuberculosis-2013 Revision. http://www.who.int/iris/bitstream/10665/79199/1/9789241505345

[43] Ryu, J.Y. (2015) Diagnosis of Pulmonary Tuberculosis: Recent Advances and Diagnostic Algorithms. Tuberculosis and Respiratory Diseases, 78, 64-71. https://doi.org/10.4046/trd.2015.78.2.64

[44] Singhal, R. and Myneedu, P.V. (2015) Microscopy as a Diagnostic Tool in Pulmonary Tuberculosis. International Journal of Mycobacteriology, 4, 1-6. https://doi.org/10.1016/j.ijmyco.2014.12.006

[45] WHO (1998) Laboratory Services in Tuberculosis Control. Part II. Microscopy. World Health Organisation, Geneva. https://doi.org/10.1186/s13104-016-2136-x http://whqlibdoc.who.int/hq//WHO_TB_98.258_(part1).pdf

[46] Helb, D., Jones, M. and Story, E. (2010) Rapid Detection of Mycobacterium tuberculosis and Rifampin Resistance by Use of On-Demand, Near-Patient Technology. Journal of Clinical Microbiology, 48, 229-237. https://doi.org/10.1128/JCM.01463-09

[47] WHO (2017) Essential Medicines and Health Products Information Portal a World Health Organization Resource.

http://apps.who.int/medicinedocs/en/d/Js4872e/6.3.html 
[48] Ogbudebe, C.L., Chukwu, J.N., Nwafor, C.C., Meka, A.O., Ekeke, N., Madichie, N.O., Anyim, M.C. and Osakwe, C. (2014) Reaching the Underserved: Active Tuberculosis Case Finding in Urban Slums in Southeastern Nigeria. International Journal of Mycobacteriology, 4, 18-24.

[49] Kasaie, P., Andrews, J.R., Kelton, D.W. and Dowdy, W.D. (2014) Timing of Tuberculosis Transmission and the Impact of Household Contact Tracing an Agent-Based Simulation Model. American Journal of Respiratory and Critical Care Medicine, 189, 845-852. https://doi.org/10.1164/rccm.201310-1846OC

[50] Tadesse, A.H., Mourik, V.M.S.M., Thomas, P.A.D. and Marc, J.M.B. (2015) Isoniazid Prophylactic Therapy for the Prevention of Tuberculosis in HIV Infected Adults: A Systematic Review and Meta-Analysis of Randomized Trials. PLoS ONE, 10, 1-16.

[51] Stefan, H.E., Kaufmann, S.H.E., Weiner, J. and Reyn, C.F. (2017) Novel Approaches to Tuberculosis Vaccine Development. International Journal of Infectious Diseases, 56, 263-267. https://doi.org/10.1016/j.ijid.2016.10.018

[52] Daginawala, A.A.H., Singh, H.F. and Rajpal, S.L.S. (2016) Current Perspective in Tuberculosis Vaccine Development for High TB Endemic Regions. Tuberculosis, 98, 149-158. https://doi.org/10.1016/j.tube.2016.03.006

[53] WHO (2016) Global Tuberculosis Report 2016. http://www.who.int/tb/publications/global_report/en/

[54] CDC (2016) Multidrug-Resistant Tuberculosis (MDR TB). https://www.cdc.gov/tb/publications/factsheets/drtb/mdrtb.htm

[55] World Bank (2015) Tuberculosis Case Detection Rate. http://data.worldbank.org/indicator/SH.TBS.DTEC.ZS

[56] FRN (2012) Report First National TB Prevalence Survey 2012, Nigeria. http://www.who.int/tb/publications/NigeriaReport_WEB_NEW.pdf

[57] Hassan, A.O. Olukolade, R., Ogbuji, Q.C., Afolabi, S.L. Okwuonye, LC., Kusimo, O.C., Osho, J.A.,Osinowo, K.A. and Ladipo,' A.O. (2017) Knowledge about Tuberculosis: A Precursor to Effective TB Control-Findings from a Follow-Up National KAP Study on Tuberculosis among Nigerians. Tuberculosis Research and Treatment, 2017, Article ID: 6309092. https://doi.org/10.1155/2017/6309092

[58] Beyanga, M., Kidenya, B.R., Gerwing-Adima, L., Ochodo,E., Mshana, S.E. and Kasang, C., (2018) Investigation of Household Contacts of Pulmonary Tuberculosis Patients Increases Case Detection in Mwanza City, Tanzania. BMC Infectious Diseases, 18, 110. https://doi.org/10.1186/s12879-018-3036-6

[59] Young, K.H., Ehman, M., Reves, R., Brandy, L., Maddox, P., Khan, A., Chorba, T.L. and Jereb, J. (2016) Tuberculosis Contact Investigations-United States, 2003-2012. Mortality and Morbidity Weekly Report, 64, 1369-1374. https://doi.org/10.15585/mmwr.mm6450al

[60] Naidoo, J. and Wills, J. (2009) Foundations for Health Promotion. 3rd Edition, Bailliere Tindall/Elsevier, Edinburgh.

[61] Woolf, H.S. and Braveman, P. (2011) Where Health Disparities Begin: The Role of Social and Economic Determinants and Why Current Policies May Make Matters Worse. Health Affairs, 30, 1852-1859. https://doi.org/10.1377/hlthaff.2011.0685

[62] Hargreaves, J.R., Boccia, D., John D.H. and Porter, J.D.H. (2011) The Social Determinants of Tuberculosis: From Evidence to Action. American Journal of Public Health, 101, 654-662. https://doi.org/10.2105/AJPH.2010.199505

[63] Canadian Institute for Health Information (2005) Select Highlights on Public Views 
of the Determinants of Health.

http://secure.cihi.ca/free_products/CPHI_Public_Views

[64] Bambra, C., Gibson, M., Sowden, A., Wright, K., Whitehead, M. and Petticrew, M. (2010) Tackling the Wider Social Determinants of Health and Health Inequalities: Evidence from Systematic Reviews. Journal of Epidemiology and Community Health, 64, 284-291. https://doi.org/10.1136/jech.2008.082743

[65] McLeroy, K.R., Steckler, A. and Bibeau, D. (1988) An Ecological Perspective on Health Promotion Programs. Health Education Quarterly, 15, 351-377. https://doi.org/10.1177/109019818801500401

[66] Meintjes, G., Schoeman, H., Morroni, C., Wilson, D. and Maartens, G. (2008) Patient and Provider Delay in Tuberculosis Suspects from Communities with a High HIV Prevalence in South Africa: A Cross-Sectional Study. BMC Infectious Diseases, 8, 72. https://doi.org/10.1186/1471-2334-8-72

[67] Omotowo, B., Ekwueme, O.C. and Aghaji, M.N. (2012) Tuberculosis Control Mechanisms and Contact Tracing: Knowledge and Practice among TB Patients at Dots Centers in Southeast Nigeria. Scientific Reports.

[68] Tlale, L., Frasso, R., Kgosiesele, O., Selemogo, M., Mothei, Q., Habte, D. and Steenhoff, A. (2016) Factors Influencing Health Care Workers' Implementation of Tuberculosis Contact Tracing in Kweneng, Botswana. The Pan African Medical Journal, 24, 229.

[69] Ekwueme, O.C., Omotowo, B. and Agwuna, K.K. (2014) Strengthening Contact Tracing Capacity of Pulmonary Tuberculosis Patients in Enugu, Southeast Nigeria: A Targeted and Focused Health Education Intervention Study. BMC Public Health, 14,1175 .

[70] Morishita, F., Eang, M.T., Nishikiori, N. and Yadav, R.-P. (2016) Increased Case Notification through Active Case Finding of Tuberculosis among Household and Neighbourhood Contacts in Cambodia. PLOS ONE, 11, e0150405. https://doi.org/10.1371/journal.pone.0150405

[71] Kambali, S., Nantsupawat, N., Lee, M. and Nugent, K. (2015) A Workplace Tuberculosis Case Investigation in the Presence of Immigrant Contacts from High Prevalence Countries. Journal of Community Health, 40, 576-580. https://doi.org/10.1007/s10900-014-9946-3

[72] Raquel, D., Neto, M., Carvalho, A. and Barros, H. (2012) Improving Tuberculosis Contact Tracing: The Role of Evaluations in the Home and Workplace. International Journal of Tuberculosis and Lung Disease, 15, 55.

[73] Lala, S.G., Little, K.M., Tshabangu, N., Moore, D.P., Msandiwa, R., Watt, M.V., Chaisson, R.V. and Martinson, N.A. (2015) Integrated Source Case Investigation for Tuberculosis (TB) and HIV in the Caregivers and Household Contacts of Hospitalised Young Children Diagnosed with TB in South Africa. PLoS ONE, 10, e0137518. https://doi.org/10.1371/journal.pone.0137518

[74] Mulder, C., Klinkenberg, E. and Manissero, D. (2009) Comparative Study on Effectiveness of Contact Tracing among Migrants and Foreign Born Population. Eurosurveillance, 14, 19.

[75] Otero, L., Shah, L., Verdonck, K., Tullia Battaglioli, T., Brewer, T., Gotuzzo, E., Seas, C. and Stuyft, P.V. (2016) A Prospective Longitudinal Study of Tuberculosis among Household Contacts of Smear-Positive Tuberculosis Cases in Lima, Peru. BMC Infectious Diseases, 16, 259. https://doi.org/10.1186/s12879-016-1616-X

[76] Crampin, A.C., Floyd, S., Ngwira, B.M., Mwinuka, V., Mwaungulu, J.N., Branson, K., Fine, P.E.M. and Glynn, J.R. (2008) A Home Tracing Program for Contacts of 
People with Tuberculosis or HIV and Patients Lost to Care. International Journal of Tuberculosis and Lung Disease, 12, 612-618.

[77] Caldeira, Z.M., Sant'Anna, C.C. and Aide, M.A. (2004) Tuberculosis Contact Tracing among Children and Adolescents. Revista de Saúde Pública, 38, 339-345. https://doi.org/10.1590/S0034-89102004000300001

[78] Makhura, O.J. (2016) Design of a USSD System for TB Contact Tracing. https://www.researchgate.net/publication/285671662_De-sign_of_a_USSD_System for_TB_Contact_Tracing

[79] Scotland, J. (2012) Exploring the Philosophical Underpinings of Research: Relating Ontology and Epistemology to the Methodology and Methods of the Scientific, Interpretive, and Critical Research Paradigms.

https://elearning.roehampton-online.com/bbcswebday/institu-tion/ukri/201620_2/

MSMMPH/MMPH00074/attachment/UKR100074Unit01Scotlandarticle.pdf

[80] Wahyuni, D. (2012) The Research Design Maze: Understanding Paradigms, Cases, Methods and Methodologies. Journal of Applied Management Accounting Research, 10, 69-80.

[81] Carla, L., Efron, M., De-mello, A., Conde, C.Q.F. and Barreto, M. (2014) Yield of Close Contact Tracing Using Two Different Programmatic Approaches from Tuberculosis Index Cases: A Retrospective Quasi-Experimental Study. BMC Pulmonary Medicine, 14, 133-140. https://doi.org/10.1186/1471-2466-14-133

[82] Harris, A.D., McGregor, J.C., Perencevich, E.N., Furuno, J.P., Zhu, J., Peterson, D.E. and Finkelstein, J. (2006) The Use and Interpretation of Quasi-Experimental Studies in Medical Informatics. Journal of the American Medical Informatics Association, 13, 16-23. https://doi.org/10.1197/jamia.M1749

[83] Jacobsen, K.H. (2011) Introduction to Health Research Methods: A Practical Guide. Jones and Bartlett Learning, Burlington.

[84] University of Florida (2015) Steps in Hypothesis Testing. http://bolt.mph.ufl.edu/6050-6052/unit-4/module-12/steps-in-hypothesis-testing/

[85] Charan, J. and Biswas, T. (2013) How to Calculate Sample Size for Different Study Designs in Medical Research. Indian Journal of Psychological Medicine, 35, 121-126. https://doi.org/10.4103/0253-7176.116232

[86] Laerd (2013) Types of Variable. https://statistics.laerd.com/statistical-guides/types-of-variable.php

[87] Watts, J.H. (2011) Ethical and Practical Challenges of Participant Observation in Sensitive Health Research. International Journal of Social Research Methodology, 14, 301-312. https://doi.org/10.1080/13645579.2010.517658 